Cartas al Director

\title{
Sarcoma de Kaposi y tratamiento antirretroviral
}

\section{Sr. Director:}

Los doctores Andreu Martínez FJ y Martínez Mateu JM han presentado recientemente en su revista un caso de sarcoma de Kaposi epidémico laríngeo en un paciente afecto de infección por el virus de la inmunodeficiencia humana $(\mathrm{VIH})^{1}$.

El caso es muy interesante, pero en la descripción del tratamiento antirretroviral se refieren algunas inexactitudes que me parece adecuado comentar.

Indica que se inició tratamiento antirretroviral utilizando dos inhibidores de la transcriptasa inversa, zidovudina y lamivudina y un inhibidor de la proteasa, abacavir. Abacavir es una inhibidor de la transcriptasa inversa análogo de nucleósido, pero no inhibidor de la proteasa.

Posteriormente se indica que el tratamiento fue cambiando y que se combinaron diversos fármacos de la misma familia, como efavirenz, estavudina y ritonavir.

Efavirenz es un fármaco inhibidor de la transcriptasa inversa no análogo de nucleósido, estavudina es un inhibidor de la transcriptasa inversa análogo de nucleósido y ritonavir es un inhibidor de la proteasa.

Resumiendo, el paciente del caso ha recibido fármacos de las tres familias principales de antirretrovirales, inhibidores de la transcriptasa inversa análo- gos de nucleósido y no análogos de nucleósido, así como inhibidores de la proteasa.

Aunque los tratamientos antirretrovirales no son estrategias que realice el oncólogo médico, dado que la revista de Oncología es leída por diversos especialistas, muchos de ellos jóvenes, pienso que el aclarar estos aspectos del tratamiento, que para nada hacen desmerecer la calidad del trabajo presentado, puede resultar interesante.

\section{F. Marcos Sánchez} Servicio de Medicina Interna. Hospital $N^{a} S^{a}$ del Prado. Talavera de la Reina. Toledo.

\section{Bibliografía}

1. Andreu Martínez FJ, Martínez Mateu JM. Sarcoma de Kaposi epidémico mucoso: aportación de un caso y revisión de la literatura. Oncología 2005; 28: 239-243.

\author{
Correspondencia: \\ Dr. F. Marcos Sánchez \\ C/ Gregorio Corrochano, 1 \\ E-45600 Talavera de la Reina (Toledo)
}

